\title{
NEUROPSYCHOLOGICAL OUTCOMES OF CORONARY ARTERY BYPASS GRAFTING
}

\author{
Nafisa Cassimjee \\ MA, PhD (Psychology) \\ Lecturer, Department of Psychology, University of Pretoria \\ Corresponding author: ncassim@postino.up.ac.za
}

\section{Caroline L Couzens}

MA (Counselling Psychology)

Postgraduate student, Department of Psychology, University of Pretoria

\section{Frans J Smith}

MBChB, MMed (Anaesth.)

Principal Consultant, Department of Anaesthetics, University of Pretoria

\section{Claire Wagner}

MA, D Phil (Psychology)

Lecturer, Department of Psychology, University of Pretoria

Keywords: neuropsychological assessment; cognitive domains; coronary artery bypass grafting; deficit measurement; rehabilitation

\begin{abstract}
People with coronary heart disease have recourse to a palliative intervention such as Coronary Artery Bypass Grafting (CABG). There is increasing recognition, however, that postoperative cerebral complications and neuropsychological decline constitute a significant proportion of adverse outcomes associated with the CABG procedure. Utilising a one-group pre- and posttest quasi-experimental design, nineteen participants undergoing elective CABG at the Pretoria Academic Hospital, were assessed on a neuropsychological test battery comprising six instruments and the Beck Depression Inventory. The main aim of the study was to investigate the neuropsychological outcomes in CABG patients after elective surgery. The secondary aim was to determine if neuropsychological outcomes correlate with quantitative electroencephalography (QEEG). The findings indicated that postoperatively, $63 \%$ of patients demonstrated cognitive change in various neuropsychological domains. A group mean analysis found significant postoperative decline on specific tasks of the Grooved Pegboard Test (GPT), the Rey Auditory Verbal Learning Test (RAVLT), and the Trail Making Test (TMT). The relationship between neuropsychological performance and the QEEG measures was not significant. The study confirms previous findings regarding selective neuropsychological postoperative performance decrement, and highlights the importance of psychological intervention in the rehabilitation process.
\end{abstract}

\section{OPSOMMING}

Persone met ' $n$ koronêre hartsiekte is soms genoodsaak om ' $n$ hartomleiding (CABG), wat ' $n$ tydelike intervensie ter verligting is, te ondergaan. Daar is egter ' $n$ toenemende bewustheid dat die serebrale komplikasies en afname in neurosielkundige funksies, wat met die CABG-prosedure verband hou, betekenisvolle ongunstige uitkomste na die chirurgie het. 'n Neurosielkundige toetsbattery, wat uit ses instrumente bestaan, en die "Beck Depression Inventory", is gebruik om die neurosielkundige uitkomste by negentien persone te ondersoek wat elektiewe hartomleidingchirurgie by die Pretoria Akademiese Hospitaal ondergaan het. Verder is ook gepoog om vas te stel of neurosielkundige uitkomste met kwantitatiewe elektroënsefalografie (KEEG) korreleer. In hierdie studie is 'n eengroep voor- en natoets kwasi-eksperimentele ontwerp gebruik. Daar is bevind dat 63\% van die pasiënte wel kognitiewe 
verandering in verskeie neurosielkundige domeine ondergaan het. ' $n$ Groepgemiddelde ontleding het betekenisvolle agteruitgang op spesifieke take van die "Grooved Pegboard Test (GPT)", die "Rey Auditory Verbal Learning Test (RAVLT)", en die "Trail Making Test (TMT)" na die chirurgie bevind. Die verhouding tussen neurosielkundige prestasie en die KEEG-meting was nie betekenisvol nie. Die navorsing bevestig vorige bevindings met betrekking tot die agteruitgang in prestasie na die CABG-prosedure en beklemtoon die belangrikheid van sielkundige intervensie in die rehabilitasieproses.

\section{INTRODUCTION AND PROBLEM STATE- MENT}

From as early as the 1920 s the beneficial effects of cardiac surgery have been documented for patients with cardiac disease. Coronary artery bypass grafting (CABG) is one intervention that has decreased mortality rates associated with cardiac problems and is successfully used to reduce angina and revascularise the heart (Selnes \& McKhann, 2001:451). There is increasing recognition, however, that $\mathrm{CABG}$ patients are more at risk for postoperative cerebral dysfunction than patients who undergo other types of major surgery (Murkin, Newman, Stump \& Blumenthal, 1995:1290). Coronary bypass procedures may contribute to lower mortality rates, but postoperative cerebral complications and neuropsychological decline constitute a significant proportion of adverse outcomes associated with the procedure (Browne, Halligan, Wade \& Taggart, 1999:481; Dijkstra, Houx \& Jolles, 1999:867).

Neuropsychological impairment following surgery is measured through the assessment of various cognitive outcomes. The neuropsychological battery usually involves measures of memory, attention, visuoconstructional capacity, and psychomotor abilities. Neuropsychological assessment of these cognitive domains is important because cognitive change may be a concomitant of underlying neurologic injury sustained during the CABG procedure (Borowicz, Maura, Goldsborough, Selnes \& McKhann, 1996:105). The aetiology of the underlying cerebral deficit is uncertain, but the precipitating and predisposing causes appear to be multifactorial. The causative agents include cerebral ischemia and hypoxia that arise from the interactions of intraoperative microemboli, cerebral hypoperfusion, surgical factors, and patient characteristics (Greenwald \& Burke, 1992:283; McKhann, Maura, Goldsborough, Borowicz, Selnes, Mellits, Enger, Quaskey, Baumgartner, Cameron, Stuart \& Gardner, 1997:515; Pearson, 1986:313; Savageau,
Stanton, Jenkins \& Klein, 1982:598; Walzer, Herrman \& Wallesch, 1997:644). In addition to the general alterations in blood flow, the cerebral hemispheres and brainstem structures are subject to hypotensive, thromboembolic, hemorrhagic, metabolic, and toxic insults that enhance susceptibility to neurologic injury (Greenwald \& Burke, 1992:284). The multifactorial influences may therefore consist of temporary biochemical and cerebral blood flow alterations or structural contusions. Surgical factors would include the length of time and the anaesthetic agents used during the surgical procedure. The latter may also contribute to short-term cognitive deficit because the proliferation of target sites of anaesthetic action in the central nervous system causes a dispersed cascade of events that modifies nerve cell processes (involved in cognition) via ion channel and receptor effects. The association between anaesthetic action and cognitive performance was evident in a group of healthy subjects who presented with impaired functioning in two unrelated memory systems after the administration of ketamine, a commonly used anaesthetic in CABG (Adler, Goldberg, Malhotra, Pickar \& Breier, 1998:814).

\section{POSTOPERATIVE COGNITIVE OUT- COMES}

A review of the literature on CABG indicates that shortterm, medium-term, and long-term neuropsychological decline occurs postoperatively. However, such findings are equivocal and characterised by discrepancies in incidence and duration of neuropsychological decline.

Incidences of short-term decline (within a month) range from $26 \%$ to $83 \%$ (Borowicz et al. 1996:106; McKhann et al. 1997:513; Selnes \& McKhann, 2001:1452; Toner, Taylor, Newman \& Smith, 1998:13). In medium- to longterm studies, the incidence ranges from zero percent to 57\% (Borowicz et al. 1996:109; Toner et al. 1998:16). Several researchers found that after a five-year testing interval, a greater frequency of patients perform below 
baseline levels (Newman, Kirchner, Phillips-Bute, Gaver, Grocott, Jones, Mark, Daniel, Reves \& Blumenthal, 2001:399; Sotaniemi, Mononen \& Hokkanen, 1986:414). Newman et al. (2001:401) concurred that neuropsychological functioning at discharge (short-term) was a significant predictor of long-term performance.

The discrepant findings are attributable to methodological incongruities among studies. These pertain to the use of different control groups, testing intervals, sample selection criteria, analysis techniques, and the composition of test batteries (Borowicz et al. 1996:107; Murkin et al. 1995:1289; Slade, Sanchez, Townes \& Aldea, 2001:5; Stump, 1995:1342). Vanninen Äikia, Könönen, Partenen, Tulla, Hartikainen, Partanen, Mannienen, Enberg and Hippeläinen (1998:624), for example, reported on group effects and found no significant deterioration postoperatively. However, their restricted analysis of group effects may have masked postoperative neuropsychological impairment. Additional individual analysis on this cohort indicated impairment in $22 \%$ of the sample. Walzer et al. (1997:645) found no short-term postoperative decline but based this result on assessment of general cognitive functioning (mini mental status exam) and specific taskbased tests for example, clock reading and naming. The sensitivity of these tests in the context of cardiac neuropsychological assessments, specifically at shortterm intervals, is negligible.

The analysis of neuropsychological performance of cardiac patients comprises the use of two techniques namely individual change analysis and group mean analysis. Individual change analysis examines individual performance over time, and group mean analysis considers the average changes for the group as a whole. Several researchers have suggested that individual change analysis is susceptible to the influences of regression toward the mean where high baseline performances are considered impaired and the ad hoc choice of a change index widens the differential between significant change and functional impairment (Browne et al. 1999:482; Slade et al. 2001:6). Furthermore, opponents of group analysis contended that group profiles conceal individual performances that are markedly lower than baseline scores (Newman, 1995:1352; Slade et al. 2001:4). Thus, some of the discrepancies in the results arise from the different conclusions that the types of analysis provide.
Psychological factors may also contribute to or mask performance on neuropsychological tests before and after surgery. The occurrence of depression in cardiac patients has been widely reported (Arrowsmith, Grocott, Reves \& Newman, 2000:383; Borowicz et al. 1996:108). However, studies have found that preoperative and postoperative changes in depression have limited influence on neuropsychological performance (Arrowsmith et al. 2000:383; Vanninen et al. 1998:625). Nonetheless, the association between depression and general psychometric test performance merits the inclusion of mood assessments in studies of cardiac procedures and neuropsychological assessments (Toner et al. 1998:16).

The investigation of cognitive change after cardiac intervention often includes methods such as quantitative electroencephalography, brain imaging techniques and biochemical markers. Electrophysiological investigations have been used in many studies to elicit information about overt and subtle signs of injury. Investigators detect and monitor electrophysiological changes in cerebral functioning between preoperative and postoperative conditions with the QEEG (Toner et al. 1998:14). Contradictory findings concerning the relationship between QEEG and neuropsychological deficit have been reported. Vanninen et al. (1998:624) found that although postoperative neuropsychological decline was associated with QEEG slowing, the relationship was not significant, whereas Toner et al. (1998:17) showed that patients who had greater change scores on neuropsychological tests were more likely to have greater QEEG deficit. Gugino, Chabot, Aglio, Aranki, Dekkers and Maddi (1999:57) confirmed the latter finding by demonstrating that at various levels of sensitivity and specificity, the intraoperative QEEG significantly predicted one-week and three-month postoperative deficit.

Neuropsychological assessment in the context of cardiac surgery has generated increasing interest. Neuropsychological measures ascertain cognitive change after brain atrophy and the sensitivity of these measures makes them useful for identifying neuropsychological changes in the absence of focal neurologic deficits. The phenomenon of neuropsychological decline after CABG, however, has received scant attention in the South African context. This implies that current rehabilitation focuses on the physical state of 
the patient, and discounts possible precipitating factors that may adversely influence recovery.

The primary aim of this study was to investigate the short-term neuropsychological change in postoperative CABG patients using group mean effects and individual change analysis. The secondary aim was to investigate the relationship between neurologic deficit, as measured by the quantitative electroencephalogram (QEEG), and neuropsychological decline.

\section{METHOD}

\section{Research design}

This neuropsychological study of a group of cardiac surgery patients required a baseline score in order to investigate change. The research setting and circumstances in which this research occurred made it difficult to employ a true experimental design. Rather, a one-group pretest-posttest quasi-experimental design was implemented. Although the one-group pretestposttest design does not include a control group or random assignment of subjects, an advantage of this design is that each participant is involved in both testing conditions so that the "effects of participant variables are perfectly balanced across conditions" (Whitley, 2002:192). All participants were exposed to the intervention between the pre- and posttests.

Extraneous variables such as practice effect, the lack of a control group and mood changes may influence the results. However, a number of strategies were included in an attempt to control for extraneous effects. Firstly, a methodological attempt to control for practice effect involved the implementation of alternate forms of certain tests in the neuropsychological battery. Secondly, the researchers included individual change analysis, which uses each individual as his or her own control, in an attempt to control for practice effect and other extraneous variables. Thirdly, the compilation of the neuropsychological test battery adhered to the statistical parameters of the reliability coefficients available for each test. Reliability coefficients provide informative data in the evaluation of change scores across assessments as they specify the likelihood of fluctuations due to measurement error (McCaffrey, Duff \& Westervelt, 2000:3). However, it should be noted that reliability coefficients are limited in assessing the influence of practice effect as the latter are a reflection of changes in the total scores, whereas reliability coefficients reflect the stability of the relative ranking of each patient's score. Neuropsychological tests were included based on their reported sensitivity to particular cognitive domains and the recommendations of previous studies.

\section{Procedure}

The Pretoria Academic Hospital was the site for this investigation and the anaesthetist involved in the cardiac procedures was included in the research team. This study formed part of a larger project that aimed to assess longterm neuropsychological and neurologic functioning utilising cognitive data and QEEG evaluations.

The researchers contacted the anaesthetist weekly to receive the details of patients due for elective CABG. The number of patients available per week varied from one to three patients. The researchers informed the patients about the study and obtained written consent from all interested individuals. The pretest was administered one day before the operation, while the posttest was conducted a week after the operation. There were two scheduled testing sessions (morning and afternoon) and each person participated at the same time of the day pre- and postoperatively. The same person administered the tests at both intervals. The researchers ensured that the patients had not taken any kind of sedative on the day of the testing. All patients were alert, orientated, and medically stable at the time of preoperative and postoperative testing .

\section{Sample}

Between May and December 2001, all the elective CABG patients at the Pretoria Academic Hospital were approached. The sample excluded patients undergoing emergency procedures and patients with a history of strokes or other neurological conditions. Twenty-six participants qualified for the study. However, seven patients did not complete the postoperative testing for the following reasons: four patients died, two patients postponed or cancelled the operation, and one patient did not have transport. Sixteen males and three females completed the pre- and postoperative testing. The participants varied in age from 39 to 66 years old, where one patient fell into the under- 40 category, three were 
between 40 and 49 years old, nine patients fell into the 50 to 59 age category, and six patients were between 60 and 69 years of age. The mean age of the sample was 55.3 years. The mean number of years engaged in formal education was 11.8 years.

\section{Test battery}

The measuring instruments (neuropsychological and depression inventory) formed a comprehensive but concise test battery. The test battery chosen for this study measured the following neuropsychological domains: memory (visual and verbal), attention, visuoconstructional ability, and motor ability (manual dexterity and psychomotor speed). In addition to evaluating a key cognitive domain, many of these tests also measure a number of overlapping functions. The choice of assessment tools was guided by the consensus criteria set out by Murkin et al. (1995:1290).

The following neuropsychological tests were implemented to measure the above domains:

- Complex Figure Test (CFT) - a measure of visuospatial constructional ability, perceptual-organisational skill, and visual perceptual memory. Alpha coefficients of .60 and .80 have been reported for the CFT copy and recall conditions, respectively (Spreen \& Strauss, 1998:353).

- $\quad$ Rey Auditory Verbal Learning Test (RAVLT) - an assessment of verbal learning and memory, specifically immediate memory span, new learning, susceptibility to interference, and recognition memory. The RAVLT is particularly sensitive to neurological damage and verbal memory deficits in a variety of patient groups (Spreen \& Strauss, 1998:331). According to Lezak (1995:442) reliability coefficients after a year have ranged from .38 to .70 , and the learning component of the RAVLT has shown significant correlations (.50 to .65) with other measures of learning and memory.

- $\quad$ Trail Making Test (TMT part A \& B) - this test is utilised to measure motor speed and attentional abilities. The reliability coefficients range from .60 to .90 (Lezak, 1995:382).

- Letter Cancellation Test (LCT) - this measure assesses the capacity for sustained attention. According to Spreen and Strauss (1998:354), low scores on this measure can indicate overall slowing in responsiveness, inattentiveness and prob- lems with response shifting associated with diffuse brain damage.

- Grooved Pegboard Test (GPT) - this is a timed test of manual dexterity and fine motor coordination. Test-retest reliability of .82 has been reported (Lezak, 1995:684).

- Digit Symbol Substitution Test (DSST) - This test taps into abilities such as motor persistence, sustained attention, response speed, and visuomotor coordination (Lezak, 1995:377). Reliability coefficients range from .82 to .88 and remain at significant levels for older adults (Lezak, 1995:378).

- Beck Depression Inventory (BDI) - this is utilised to monitor the changes in depressive scores and their effect on cognitive performance. In a variety of patient groups, test- retest reliability coefficients range from .74 to .83; and when compared to clinical ratings a validity coefficient of .66 has been reported (Lezak, 1995:777). In a neuropsychological setting the BDI has limitations as a specific measure of depression amongst the elderly (Spreen \& Strauss, 1998:605). Endler, Macrodimitris and Kocovski (2000:28) point out that seven of the 21 items refer to somatic symptoms and this can lead to misinterpretation if a patient has a physical ailment.

The administration of the neuropsychological battery and the depression scale as a first instrument was determined on a random basis. The entire battery took approximately 50 minutes to administer.

Individuals underwent the neurological assessment (QEEG) in the same preoperative and postoperative time periods that was used for neuropsychological testing. A change greater than $20 \%$ denoted the change index for significant decline in QEEG scores. The frequency bands yielded six composite scores, and a $20 \%$ change in two or more of the frequency composites provided an index of significant decrement on the QEEG measure.

\section{Data analysis}

Two forms of analysis dominate research on neuropsychological performance after cardiac surgery. Owing to the controversy in the literature about the advantages of interpreting group effects or individual change indices, both group and individual change analyses were 
implemented.

In terms of group effects, significant neuropsychological change was determined by comparing the mean change scores in the two conditions. Nonparametric statistical tests were used due to the small sample size and the slightly skewed population distributions. The Wilcoxon Sign Test generates descriptive means and determines statistically significant group differences. A significance level was set at $\underline{p}<0.05$ for all comparisons. The Wilcoxon Sign Test is appropriate for this specific study as it does not make any assumptions about the form of the distribution of differences, nor does it assume that all subjects derive from the same population. This test is also conducive to a single-group pre- and posttest analysis where subjects act as their own controls (Jaccard \& Becker, 2002:471; Siegel, 1956:68). The disadvantage of using group comparisons lies in its failure to take into account learning or practice effects (Newman, 1995:1352). Although alternative forms of the neuropsychological tests were used, this strategy does not cancel completely the effects of practice.

Individual change in neuropsychological performance is an alternative strategy to account for deficit measurement after cardiac surgery. This method necessitates the use of a cut-off criterion to determine the degree of change that is commensurate to deficit classification. As there are no definite criteria reflecting the degree of change that warrants a classification of deterioration, the choice of a cut-off criterion is relatively arbitrary and hails from epidemiological studies that use the standard deviation method (McKhann et al. 1997:512). This ad hoc decision for defining significant cognitive decrement underscores the endorsement of researchers that this cut-off criterion does not imply a definition of dysfunction or impairment but rather signifies a threshold that contains more scientific than clinical significance.

Researchers have frequently used two indices of deficit. Most consistently, these are: (a) the standard deviation method ( $0.5 \underline{S D}$ and one $\underline{S D}$ ) where a postoperative decline in a patient's performance of more than the relevant standard deviation from the group's baseline or preoperative score indicates impairment; and (b) the percentage change (generally $20 \%$ ) where a decline of more than the relevant percentage on the individual's preoperative score indicates impairment. The use of the $0.5 \mathrm{SD}$ is considered restrictive and more susceptible to the masking effects of practice. The $20 \%$ and $1 \underline{\mathrm{SD}}$ are considered similar cut-off thresholds for change, and after deliberation the $1 \underline{\mathrm{SD}}$ criteria was used in this study to signify the change threshold. The $1 \underline{\mathrm{SD}}$ change criteria utilises a comparative technique where individual change scores are set against the group norm, and this affects scores that are low at preoperative testing relative to the baseline group mean score (Borowicz et al. 1996:109). For this reason the use of a comprehensive, sensitive and precise neuropsychological test battery is integral to the determination of cognitive change.

Significant change is therefore defined as a $1 \underline{\mathrm{SD}}$ decline from the preoperative score. The score declines are also considered according to the number of tests that indicate lower postoperative scores. Various criteria have been used to determine the number of tests that constitute a decline. The length of the test battery is relevant here. In most studies 10 tests are used because of the time factor and from these a decline in two out of five tests to two out of 10 tests constitute change (for example, Toner et al. 1998:15). For this study, significant change translated into a decline greater than $1 \mathrm{SD}$ from baseline scores on two or more tests in the battery. This study deviated from the general trend of a $20 \%$ failure on the entire battery and adhered to a more stringent criterium (33\%) as an index of change.

\section{RESULTS}

Neuropsychological decline after CABG was found using both individual change analysis and group mean analysis.

\section{Group effects}

A comparison of pre- and postoperative group effects showed significant differences in six out of the 22 variables. Tables 1 to 4 show the results obtained for each cognitive domain.

The Grooved Pegboard Test (GPT) and Digit Symbol Substitution Test (DSST) measured aspects pertaining to motor abilities such as manual dexterity (fine movement) and psychomotor speed. From the summarised results in Table 1 , it is evident that 
Table 1: Difference scores by cognitive domain - Motor functions

\begin{tabular}{|l|l|l|l|l|}
\hline Test & $\begin{array}{l}\text { Preoperative } \\
\text { Mean (SD) }\end{array}$ & $\begin{array}{l}\text { Postoperative } \\
\text { Mean (SD) }\end{array}$ & $\begin{array}{l}\text { Difference Mean } \\
(\text { SD })\end{array}$ & $p$ Values \\
\hline $\begin{array}{l}\text { Motor speed } \\
\text { GPT (DH) }\end{array}$ & $-116.05(20.77)$ & $139.00(27.82)$ & $-22.95(45.26)$ & $0.007^{*}$ \\
\hline $\begin{array}{l}\text { GPT (NDH) } \\
\text { Psychomotor } \\
\text { speed } \\
\text { DSST }\end{array}$ & $-124.05(19.64)$ & $143.61(36.97)$ & $-19.56(24.42)$ & $0.001^{*}$ \\
\hline
\end{tabular}

$\mathrm{DH}$ - dominant hand

$\mathrm{NDH}$ - nondominant hand

*Significant, $p<0.05$

Table 2: Difference scores by cognitive domain - Memory (Verbal and Visual)

\begin{tabular}{|l|l|l|l|l|}
\hline Test & $\begin{array}{l}\text { Preoperative } \\
\text { Mean (SD) }\end{array}$ & $\begin{array}{l}\text { Postoperative } \\
\text { Mean (SD) }\end{array}$ & $\begin{array}{l}\text { Difference Mean } \\
\text { (SD) }\end{array}$ & $p$ Values \\
\hline $\begin{array}{l}\text { Visual M } \\
\text { CFT }\end{array}$ & & & & \\
\hline 30 s recall & $19.66(6.23)$ & $19.92(6.73)$ & $-0.26(6.33)$ & 0.896 \\
\hline 30 m recall & $19.81(6.37)$ & $18.63(6.83)$ & $1.18(7.07)$ & 0.286 \\
\hline $\begin{array}{l}\text { Verbal M } \\
\text { RAVLT }\end{array}$ & & & & \\
\hline Trial 1 (A) & $5.47(2.52)$ & $5.68(1.80)$ & $-0.21(2.7)$ & 0.689 \\
\hline Trial 2 & $7.89(2.02)$ & $7.58(2.27)$ & $0.32(1.7)$ & 0.479 \\
\hline Trial 3 & $9.05(2.95)$ & $8.37(2.85)$ & $0.68(3.06)$ & 0.487 \\
\hline Trial 4 & $9.74(2.81$ & $9.47(2.76$ & $0.26(2.33)$ & 0.601 \\
\hline Trial 5 & $10.53(2.37)$ & $9.26(2.38)$ & $1.26(2.16)$ & $0.025^{*}$ \\
\hline Distr (B) & & $4.11(1.63)$ & $0.42(1.89)$ & 0.357 \\
\hline Trial 6 & $8.00(3.42)$ & $6.53(3.49)$ & $1.48(3.32)$ & 0.082 \\
\hline Trial 7 & $8.68(3.45)$ & $6.32(3.37)$ & $2.37(2.79)$ & $0.002^{*}$ \\
\hline Recog. (A) & $12.95(2.04)$ & $11.59(2.46)$ & $1.22(3.26)$ & 0.113 \\
\hline $\begin{array}{l}\text { Recog. } \\
\text { (Mixed) }\end{array}$ & $39.28(5.24)$ & $32.42(8.15)$ & $6.78(5.90)$ & $0.000^{*}$ \\
\hline
\end{tabular}

${ }^{*}$ Significant, $p<0.05$

patients demonstrated significant decline $(\underline{p}<0.05)$ on the GPT only for both the dominant and nondominant hands (DH and $\mathrm{NDH})$.

The memory domain consisted of visual and verbal memory tests, namely the Complex Figure Test (CFT) and the Rey Auditory Verbal Learning Test (RAVLT). Table 2 shows that the difference in the number of words recalled on trails 5 and 7 , and the mixed recognition was statistically significant for the two testing conditions. Patients improved their scores on the 30 -second recall trial of the CFT $(-0.26)$ and trial $1(A)$ of the RAVLT 
$(-0.21)$. This may indicate a practice effect, as patients are aware on the second administration that they will be asked to recall the figure and words. Of note, trial 1 of the RAVLT, which taps into attention processes, patients showed improvement, which supports the results found for the TMT (part A) and LCT (errors).

Attention was measured using the Trail Making Test (part A and B), the Letter Cancellation Test (LCT) and the DSST. Patients demonstrated significant cognitive decline $(\underline{p}<0.05)$ on the TMT part B (errors), a task that taps into the tracking and scanning processes of attention (divided attention). Patients showed an improvement (-1.2) in scores for the TMT part A and the number of errors on the LCT, but these were not statistically significant. Sustained attention, as measured by both the LCT and DSST, showed no statistically significant changes.

The copy trial of the Complex Figure Test (CFT) was used to measure aspects of visuoconstruction. No significant neuropsychological decline $(\underline{p}<0.05)$ was found on the CFT-copy (Table 4).

In summary, the study found statistically significant decrements $(\underline{p}<0.05)$ on measures of motor dexterity, divided attention and verbal memory.

\section{Individual change scores}

The frequency and percentage of patients with decline was identified in accordance with the $1 \underline{\mathrm{SD}}$ criterion. A week after surgery, $63 \%$ of patients showed cognitive decline on at least one test.

Table 5 indicates that the change differential between group effects and individual analysis is biased, with individual analysis showing greater evidence of postoperative decline. No significance was reported for visual memory on group profiles, but independent profiles suggest that eight patients registered changes in CFT scores. Fifty-three percent of the sample showed postoperative deterioration on scores of divided attention, while less than a fifth of the patients showed changes on psychomotor speed. Therefore, the incidence of decline suggests that over half of the patients in the sample show changes in cognitive performance but the frequency of change is characterised by domain speci- ficity. Dijkstra et al. (1999:872) reported that there is often a discrepancy between a patient's complaint about specific cognitive impairment and performance on tests; there appears to be more subjective evaluations of decline than actual decline on tests. This may be attributable to group analysis masking impairment or the overall insensitivity of tests.

\section{Extraneous factors}

The Beck Depression Inventory (BDI) was used to measure depression. No significant change occurred postoperatively $(\underline{p}<0.05)$, and no significant relationship between depression and neuropsychological performance was found to exist. This confirms the findings of Vingerhoets, De Soete and Jannes, (1995:199), who reported no significant differences in pre- and postoperative depression scores using the same inventory.

The effects of age, education level, and depression on difference scores were analysed using correlation coefficients. Apart from a moderate correlation between age and TMT error (Part $A$ ), which was significant $(p<0.05)$, no other significant correlations emerged between these factors and difference outcomes. Therefore, separate analyses on pre- and postoperative scores were not implemented.

\section{Neuropsychological decline and QEEG analysis}

The secondary aim of this study was to assess the relationship between neuropsychological and QEEG decline. Following the method described by Toner et al. (1998:15), individual change scores that corresponded with the 1 SD decline criterion and the $33 \%$ failure on the test battery entailed a classification of performance decrement for each patient. Deficit on the neuropsychological battery correlated with the number of QEEG channels that showed a significant difference on two of the six composites derived from the frequency bands. No significant relationship between neuropsychological outcomes and QEEG measures was found one week after surgery.

\section{DISCUSSION}

This study found domain-specific neuropsychological 
Table 3: Difference scores by cognitive domain - Attention

\begin{tabular}{|l|l|l|l|l|}
\hline Test & $\begin{array}{l}\text { Preoperative } \\
\text { Mean (SD) }\end{array}$ & $\begin{array}{l}\text { Postoperative } \\
\text { Mean (SD) }\end{array}$ & $\begin{array}{l}\text { Difference Mean } \\
\text { (SD) }\end{array}$ & $p$ Values \\
\hline \multicolumn{2}{|l|}{ Divided attention (tracking) TMT A/B } \\
\hline Time (s) & $41.37(18.64)$ & $42.63(20.17)$ & $-1.2(13.14)$ & 0.731 \\
\hline No. of errors & $0 \quad(0)$ & $0.16(0.37)$ & $-0.16(0.37)$ & 0.25 \\
\hline Time (s) & $112.63(58.07)$ & $141.47(101.65)$ & $-28.84(56)$ & 0.08 \\
\hline No. of errors & $0.63(1.01)$ & $1.42(1.74)$ & $-0.79(1.58)$ & $0.031^{*}$ \\
\hline Sustained attention - LCT & $13.21(15.04)$ & $8.95(7.62)$ & $4.2(11.44)$ & 0.256 \\
\hline No. of errors & $5.21(0.79)$ & $4.89(1.20)$ & $0.32(0.89)$ & 0.172 \\
\hline Paragraphs &
\end{tabular}

*Significant, $p<0.05$

Table 4: Difference scores by cognitive domain - Visuoconstruction

\begin{tabular}{|l|l|l|l|l|}
\hline Test & $\begin{array}{l}\text { Preoperative } \\
\text { Mean (SD) }\end{array}$ & $\begin{array}{l}\text { Postoperative } \\
\text { Mean (SD) }\end{array}$ & $\begin{array}{l}\text { Difference Mean } \\
\text { (SD) }\end{array}$ & $\boldsymbol{p}$ Value \\
\hline CFT - copy & $33.89(2.5)$ & $32.76(2.70)$ & $1.13(2.25)$ & 0.051 \\
\hline
\end{tabular}

Table 5: Frequency of outcome changes in each domain

\begin{tabular}{|l|l|l|}
\hline Domain & No. decline & \% decline \\
\hline Motor speed (GPT) & 7 & 37 \\
\hline Psychomotor speed (DSST) & 3 & 16 \\
\hline Visual memory (CFT) & 8 & 42 \\
\hline Verbal memory (RAVLT) & 9 & 47 \\
\hline Divided attention (TMT) & 10 & 53 \\
\hline Sustained attention (DSST; LCT) & 8 & 52 \\
\hline Visuoconstruction (CFT-copy) & 3 & 16 \\
\hline
\end{tabular}

performance deficits that are consistent with results from other studies. Significant functional deficit arose in the motor, attention, and memory components of cognitive functioning one week after CABG surgery. However, there was no statistically significant relationship between the functional and cerebral referents as measured by the neuropsychological battery and QEEG, respectively. Although the QEEG measures may correlate with long-term neuropsychological functioning, this neurological test appears to be a negligible predictor of short-term performance. This may arise because of the transient recovery changes occurring in brain functioning immediately after surgery.

The central nervous system substrates for neuropsychological decline appear to be multifactorial. Neuropsychological performance changes may be attributable to cerebral vulnerability to perioperative correlates such as anoxia, ischemia, and macroemboli (Gill \& Murkin, 1996:95; Greenwald \& Burke, 1992:284). The changes in specific cognitive abilities may arise from neurologic insult to key brain networks and the vulnerability of these areas to patient risk factors such as age. In studies utilising non-surgical elderly populations, neuropsychological deficits predominate in domains of memory and attention. Normal age-related cortical changes may enhance the intraoperative susceptibility of brain areas involved in memory, attention, and motor processes (Villareal \& Morris, 1998:144).

In a retrospective analysis of the literature, Zacny, Lichtor and Kortilla (1992:649) reported that anaesthetic use in surgical procedures often preceded psychomotor and cognitive effects. In addition, positron emission 
tomography (PET) scans have shown associated action between anaesthesia and significant activation in the anterior cingulate cortex, a limbic area known to mediate aspects of motor and cognitive function (Halsey, 1997:11). Support for this comes from results that show significant correlations between scores on neuropsychological tests that include an evaluative component of manual dexterity and attention span (Spreen \& Strauss, 1998:254). For example, this study found postoperative decline on the GPT and the TMT (Part B). The latter considered a test of psychomotor functions and the former a test of attention and elements of motor ability.

In the complex domain of memory, statistically significant decline was found for the learning rate and recall abilities of the patients after surgery. Although this study did not consider long-term performance, Newman et al. (2001:397) found that five years after surgery, $42 \%$ of patients performed below baseline on domains such as memory, attention, and other executive functions. Significant difference for the TMT Part B indicated a patient's inability to execute and modify plans of action and maintain multiple trains of thought simultaneously. The inability to shift from one salient aspect to another relates to pre-frontal functioning, thereby implicating the role of initiation, decision-making, and self-monitoring in other words executive functioning (Damasio, 1994:61; Mirsky, 1996:81). Since most of the patients showed changes in scores influencing these processes, the implications for everyday functioning rest on the nature of these deficits. In other words, the transient or permanent nature of the cognitive outcomes would determine whether significant change translated into functional impairment.

Neuropsychological decline appears to delineate along broad cognitive domains. Based on this specificity the anatomical substrates of neuropsychological deficit may include the frontal cortex and its reciprocal relationships between major functional systems - the sensory systems of the posterior cortex, the effector mechanisms of the motor system and the limbic memory system with its interconnections to the subcortical areas involved in arousal, affective, and motivational states. Multifactorial intraoperative agents appear to compromise the functioning of the systems responsible for cognitive processes. These postoperative neuropsychological outcomes have several therapeutic implications.

Being aware of subtle postsurgical cognitive deficits may induce stressful responses in patients and a destructive cycle may occur where this stress impacts further on cardiac recovery (Donker, 2000:927; McKibbin \& Pretorius, 2002:22). Advances in surgical procedures have included the use of neuroprotective agents to minimise adverse effects on central nervous system functioning. However, most of the attention after surgery focuses on physical rehabilitation. Postoperative rehabilitation strategies should include a psychological component that could be modified to individual variations in neurosusceptibility. This will ensure that both physical and cerebral well-being are fully realised. For effective intervention, counsellors should consider the patient's premorbid profile, current cognitive status, and potential long-term impact of change outside the hospital setting. The course of therapeutic intervention should be based on whether deficits translate into impaired everyday functioning.

\section{LIMITATIONS AND RECOMMENDATIONS}

- Neuropsychological research creates an inherent paradox. Damage to areas of the cortex can cause deficits in specific sequences of thought, emotion, and behaviour. However, a limited knowledge of the functional organisation of cognitive systems, their resilience and vulnerability to atrophy, and the complexity of their working rationale challenges any inferences that link cognitive changes to specific areas and to classification of functional impairment. Brooks (1999:7) suggests that this theoretical drawback should be evaluated against the trend that any significant results obtained instigates further theoretical inferences, particularly in a contemporary discipline like neuropsychology. In this study, performance decrement occurred in domain-specific cognitive processes, but the actual cause of this or its translation into functional impairment requires further investigation. However, taking into account the subjective claims of patients regarding postoperative cognitive changes and the incidence of this in short-term evaluations, one can hypothesise that some predisposing or precipitating complications in bypass grafting adversely affects the central nerv- 
ous system and neuropsychological processes.

- The lack of an appropriate control group and small sample size compromised the estimation and correction of practice effects. Moreover, although research has not found evidence that mood variables influence test performance, more robust mood scales relevant to cardiac patients are needed. The possibility exists that ambiguous interpretations can be made for items on the BDI as these items refer to somatic symptoms that may be similar to the physical signs of cardiac problems (Cavenaugh, Clark \& Gibbons, 1983:810; Murkin et al. 1995:1292).

- Future studies need to incorporate long-term evaluations in order to ascertain the consistency of deficit measurements. This, together with the use of neurological correlates (QEEG, MRI scans), would provide insight into the mechanisms underlying change in performance and its functional impact on patients.

\section{CONCLUSION}

The findings of this study attest to the importance of neuropsychological evaluations in the context of cardiac surgery. Significant neuropsychological decrement was demonstrated in key cognitive domains that may have long-term consequences for executive functioning. This study provides a useful springboard for future investigations that could yield valuable information for cardiac patients, their families, and the professionals tasked with their therapeutic rehabilitation.

\section{LIST OF REFERENCES}

ADLER, CM; GOLDBERG TE; MALHOTRA, AK; PICKAR, D \& BREIER, A 1998: Effects of ketamine on thought disorder, working memory and semantic memory in health volunteers. Biological Psychiatry, 43:811-816.

ARROWSMITH, JE; GROCOTT, HP; REVES, JG \& NEWMAN, MF 2000: Central nervous system complications of cardiac surgery.

British Journal of Anaesthesia, 84(3):378-392.

BOROWICZ, LM; MAURA, MS; GOLDSBOROUGH, RN; SELNES, OA \& MCKHANN, GM 1996: Neuropsychologic change after cardiac surgery: A critical review. Journal of Cardiothoracic and Vascular Anesthesia, 10(1):105-112.

BROOKS, JL 1999: The neuropsychological approach: Some con- siderations. [Online]. Available:www//istsocrates.berkeley.edu/ jlbrooks/neuropsych1999.pdf. Accessed on 12 September 2002. BROWNE, SM; HALLIGAN, PW; WADE, DT \& TAGGART, DP 1999: Cognitive performance after cardiac operation: Implications of regression towards the mean. Journal of Thoracic and Cardiovascular Surgery, 117(3):481-485.

CAVENAUGH, SV; CLARK, DC \& GIBBONS, RD 1983: Diagnosing depression in the hospitalized medically ill. Psychosomatics, 24:809-815.

DAMASIO, AR 1994: Descartes' Error. Emotion, Reason, and the Human Brain. New York: Putnam.

DIJKSTRA, JB; HOUX, PJ \& JOLLES, J 1999: Cognition after major surgery in the elderly: Test performance and complaints. British Journal of Anaesthesia, 82(6):867-874.

DONKER, FJS 2000: Cardiac rehabilitation: A review of current developments. Clinical Psychology Review, 20(7):923-943.

ENDLER, NS; MACRODIMITRIS, D \& KOCOVSKI, N 2000: Depression: The complexity of self-report measures. Journal of Applied Biobehavioural Research, 5(1):26-46.

GILL, R \& MURKIN, JM 1996: Neuropsychologic dysfunction after cardiac surgery: What is the problem? Journal of Cardiothoracic and Vascular Anesthesia, 10(1):91-98.

GREENWALD, MD \& BURKE, J 1992: Neurologic complications of cardiac surgery. (In: Kotler, MN \& Alfieri, A eds. 1992: Cardiac and noncardiac complications of open heart surgery: Prevention, diagnosis, and treatment. New York: Futura, pp 281-298).

GUGINO, LD; CHABOT, RJ; AGLIO, LS; ARANKI, S; DEKKERS, R \& MADDI, R 1999: QEEG changes during cardiopulmonary bypass: Relationship to postoperative neuropsychological function. Clinical Electroencephalography, 30(2):53-63.

HALSEY, M 1997: The perturbations of various CNS functions by anaesthetic drugs. Acta Anaesthesiologica Scandinavia, 41(1):11-12.

JACCARD, J \& BECKER, MA 2002: Statistics for the behavioral sciences; 4th edition. Belmont: Wadsworth.

LEZAK, M 1995: Neuropsychological assessment; $3^{\text {rd }}$ edition. New York: Oxford.

MCCAFFREY, RJ; DUFF, K \& WESTERVELT, HJ 2000: Practitioner's guide to evaluating change with neuropsychological assessment instruments. New York: Kluwer Academic.

MCKIBBIN, EC \& PRETORIUS, HG 2002: Stress and the heart: A coconstruction of new lifestyles after coronary heart disease (CHD). Health SA Gesondheid, 7(1):21-32.

MCKHANN, GM; MAURA, MD; GOLDSBOROUGH, A; BOROWICZ, LM; SELNES, AA; MELLITS, ED; ENGER, C; QUASKEY, SA; BAUMGARTNER, WA; CAMERON, DE; STUART, RS \& GARDNER, TJ 1997: Cognitive outcome after coronary artery bypass: A oneyear prospective study. Annals of Thoracic Surgery, 63:510515. 
MIRSKY, AF 1996: Disorders of attention: A neuropsychological perspective. (In: Reid-Lyon, G \& Krasnegor, NA eds. 1996: Attention, memory, and executive function. Baltimore: Maryland, pp 71-96).

MURKIN, JM; NEWMAN, SP; STUMP, DA\& BLUMENTHAL, JA 1995: Statement of consensus on assessment of neurobehavioural outcomes after cardiac surgery. Annals of Thoracic Surgery, 59:1289-1295.

NEWMAN, SP 1995: Analysis and interpretation of neuropsychologic tests in cardiac surgery. Annals of Thoracic

Surgery, 59:1351-1355.

NEWMAN, MF; KIRCHNER, JL; PHILLIPS-BUTE, B; GAVER, V; GROCOTT, H; JONES, RH; MARK, DB; DANIEL, B; REVES, JG \& BLUMENTHAL, JA 2001: Longitudinal assessment of neurocognitive function after coronary-artery bypass surgery. New England Journal of Medicine, 344(6):395-402.

PEARSON, DT 1986: Microemboli: Gaseous and particulate. (In: Taylor, KM ed. 1986: Cardiopulmonary Bypass. London: Chapman \& Hall, pp 313-353).

SAVAGEAU, JA; STANTON, BA; JENKINS, CD \& KLEIN, MD 1982: Neuropsychological dysfunction following elective cardiac operation. Journal of Cardiovascular Surgery, 84:585-594.

SELNES, OA \& MCKHANN, GM 2001: Coronary-artery bypass surgery and the brain. New England Journal of Medicine, 344(6):451-452.

SIEGEL, S 1956: Nonparametric statistics for the behavioural sciences. London: McGraw-Hill Kogakusha.

SLADE, P; SANCHEZ, P; TOWNES, B \& ALDEA, GS 2001: The use of neurocognitive tests in evaluating the outcome of cardiac surgery: Some methodological considerations. Journal of Cardiothoracic and Vascular Anesthesia, 15(1):4-8.

SOTANIEMI, KA; MONONEN, H \& HOKKANEN, TE 1986: Long-term cerebral outcome after open heart surgery: A five-year neuropsychologic study. Stroke, 17:410-416.

SPREEN, O \& STRAUSS, E 1998: A compendium of neuropsychological tests. Administration, norms, and commentary; $2^{\text {nd }}$ edition. New York: Oxford University Press.

STUMP, DA 1995: Selection and clinical significance of neuropsychologic tests. Annals of Thoracic Surgery, 59:13401344.

TONER, I; TAYLOR, KM; NEWMAN, S \& SMITH, PLC 1998: Cerebral functional changes following cardiac surgery: Neuropsychological and EEG assessment. European Journal of Cardio-Thoracic Surgery, 13:13-20.

VANNINEN, R; ÄIKIÄ, M; KÖNÖNEN, M; PARTENEN, K; TULLA, H; HARTIKAINEN, P; PARTANEN, J; MANNIENEN, HH; ENBERG, P \& HIPPELÄINEN, M 1998: Subclinical cerebral complications after coronary bypass surgery. Journal of Neurology, Neurosurgery, and Psychiatry, 62:644-648.
VILLAREAL, DT \& MORRIS, JC 1998: The diagnosis of Alzheimer's disease. Alzheimer's Disease Review, 3:142-152.

VINGERHOETS, G; DE SOETE, G \& JANNES, C 1995: Relationship between emotional variables and cognitive test performance before and after open-heart surgery. Clinical Neuropsychologist, 9(2):198-202.

WALZER, T; HERRMANN, M \& WALLESCH, CW 1997: Neuropsychological disorders after coronary bypass surgery. Journal of Neurology, and Psychiatry, 62:644-648.

WHITLEY, BE 2002: Principles of research in behavioural science; 2nd edition. Boston: McGraw Hill.

ZACNY, JP; LICHTOR, JL \& KORTTILA, K 1992: Psychological and neurological disturbances related to anaesthesia. Baillière's Clinical Anaesthesiology, 6(3):645-661. 